\title{
ONTMOETINGEN MET HET BOEK IN CURAÇAO'S VERLEDEN
}

\author{
Openingsrede van de Boekenweek Curaçao r96o
}

Weinig heb ik kunnen vermoeden dat ik op mijn geboorte-eiland en in het kader van een boekenweek als uitgangspunt van een causerie zou gaan kiezen juist de woorden, die ik jaren geleden in Madrid heb gebruikt om een lezing over verspreiding van cultuur te besluiten. Ik zei toen namelijk dat ik mij in Spanje beschouwde als te leven tussen twee zeeën in, met name de Atlantische Oceaan, de zee van het ongewisse, van het avontuur, en de Middellandse Zee, de zee der oude culturen. Tussen deze zeeën in heb ik, veilig genesteld in de schoot van het Oude Iberia, mij gelaafd aan de bron van een oude beschaving, die de geest verruimt en het hart ontvankelijk maakt voor de vonk der liefde en van het begrip.

Men denke niet dat dit vage beeldspraak is, zonder de ondergrond der realiteit. Voor Columbus en andere ontdekkingsreizigers na hem, is de Atlantische Oceaan immers geweest: de zee van het onbekende, de zee van de machtige zuilen van Hercules die, met hun gebiedende opschrift 'Non plus ultra' waarschuwden niet verder te gaan, terwijl de Middellandse Zee - symbool en werkelijkheid van kennis en zekerheid, van menselijk contact en verruiming van inzicht, cultuur en handel - juist noodde en lonkte ...

Wie zou durven ontkennen dat er een onweerstaanbare bekoring uitgaat van landen om de Middellandse Zee, bakermat van de westerse beschaving, die deze 'Mare Nostrum' zoals de oude Romeinen haar noemden, bestempelt tot de Zee der Cultuur bij uitstek?

Als haast iedere vergelijking gaat ook deze ergens mank, maar men zou kunnen stellen dat ook onze contreien hun 'Ma re Nostrum', hun Middellandse Zee, kennen. Grillig van vorm en weids van geest en omvang ligt zij voor ons: de Caraïbische Zee, ook wel genoemd de Zee der Antillen. 
Men zou van mening kunnen verschillen omtrent de graad van overeenkomst, men kan nimmer ontkennen dat zich in de loop der jaren een actieve uitwisseling van cultuur heeft voltrokken over de wateren van de Caraïbische Zee, dezelfde die, eeuwen her, de kust heeft bespoeld van het land der oude Azteken met hun boeiende geschiedenis en beschaving.

Als wij bij de historische feiten stil staan, dan worden wij, enerzijds, met trots - stille, waardige trots - vervuld; aan de andere kant kunnen wij slechts met moeite het schaamrood tegenhouden als wij beseffen dat de loop der jaren, op dit gebied, eerder een teruggang heeft betekend dan een gestadige groei zoals, redelijkerwijs gesproken, te verwachten zou zijn geweest.

Ons eilandje, Curaçao, heeft namelijk een zeer belangrijke rol gespeeld in de cultuurspreiding waarvan ik zo net heb gewaagd. Curaçao is - beseffen wij, de landskinderen, dit wel voldoende? cultuurcentrum geweest voor heel spaanssprekend Zuid-Amerika. Deze rol, die ons eiland indertijd op een waardige en doeltreffende wijze heeft vervuld, heeft ons, m.i., ook een verplichting opgelegd, een verplichting die wij, hélaas, niet of niet voldoende zijn nagekomen. Wij hebben het vertrouwen van toen niet volledig of niet voldoende gehonoreerd en, hoe onprettig voor ons ook, dit mag toch wel gezegd worden in het kader van een boekenweek.

De rol die Curaçao zich toen heeft aangemeten, betrof het terrein van het boek, het boek in absolute zin zowel als in een zuiver materieel-technische zin. Op Curaçao werden boeken gedrukt voor een groot deel van Zuid-Amerika. Curaçao durfde het toen aan om drukwerken te verzorgen, die ons nu, jaren later, nóg vervullen met bewondering. Boeken op allerlei gebied, van muziekschrift tot novellen, wetenschappelijke verhandelingen, geillustreerde week- en maandbladen, economische beschouwingen, minnedicht en herdrukken toe, hebben hun weg gevonden van ons dorre eiland naar de volken van het vasteland, voor wie, in culturele zin, dat dorre eiland benoorden de kust van Venezuela dan toch een oase kon worden genoemd. Van Curaçao is dus cultuur uitgegaan, Curaçao is cultuur- en kennisverspreider geweest, jaren lang.

In dit verband is het misschien aardig hierbij aan te tekenen, dat één gedachte mij nooit heeft losgelaten sinds ik, als jongeman van zestien jaar, voor het eerst het boek Del Curaçao que se va van onze eilandgenoot John de Pool onder ogen kreeg. Strikt 
genomen, dient deze titel in het Nederlands te luiden: Van het verdwijnend Curafao; dit zou taalkundig juist zijn. Maar wie verklaart mij nu de reden - taal, geest en mystiek zijn nauw met elkaar verweven - waarom ik, die toen een zeer elementaire en begrensde kennis van Spaans bezat, prompt deze titel, voor mijzelf, vertaalde: 'Van Curafao gaat het uit', in de zin dat er iets uit gaat van Curaçao. Deze vrijheid is taalkundig niet te verantwoorden en toch ... men zou het hebben kúnnen zeggen: 'Del Curaçao es que se va ...'

Wij kunnen in I 960 slechts betreuren dat ons Antilliaanse volk, blijkbaar, nimmer interesse heeft gehad voor zijn eigen cultuurgeschiedenis en vaak, ik zou haast zeggen, moorddadig met bronnen en documenten is omgesprongen. Voor de algemene geschiedenis van deze eilanden - ieder afzonderlijk zo trots op zijn zelfstandigheid en eigen bestaan - ware het te verkiezen geweest indien wij minder roekeloos en onverschillig met zoveel bronnen zouden zijn omgegaan.

De wordingsgeschiedenis van het boek op Curaçao is moeilijk na te gaan, althans op een geordende en wetenschappelijk verantwoorde wijze, omdat zich zoveel hiaten voordoen dat het haast ondoenlijk is. Verbeeldingskracht is zeker nodig om, thans, deze leemten te vullen. Toch vertrouw ik erop dat ter zake deskundige mensen - ik denk bij voorbeeld aan onze jeugdige en dynamisch aangelegde bibliothecaressen, de dames Daphne Labega en Rose Marie de Paula en anderen, die zich met de geschiedenis van deze eilanden bezig houden - gaandeweg voor het nageslacht die geschiedenis zullen weten op te tekenen en haar zoveel mogelijk zullen weten te verluchten met bewijsstukken, die, wellicht, nog bij particulieren te krijgen zijn.

In de loop van zijn soms woelige bestaan, heeft Curaçao vele drukkerijen gekend. Geen boek - in de moderne betekenis zonder een drukkerij. Het past dan ook hieromtrent het een en ander te zeggen. Een ontmoeting met het boek in Curaçao's verleden is, welhaast, niet mogelijk zonder kennismaking met het drukkerijwezen op dit eiland.

Curaçao's eerste drukkerij heeft, in zijn moderne gedaante, veel gedaan voor het boek. De Curaçaosche Courant (Drukkerij) is, bovendien, op bijzonder innige wijze verbonden met deze Boekenweek I960. $\mathrm{Zij}$ is de drukster van het programmaboekje van ons boekenfeest.

Lichten wij, in de goede betekenis van de uitdrukking, de 
doopceel van de Drukkerij De Curaçaosche Courant, die nu staat aan de William Leestraat, dan zien wij dat deze oudste drukkerij van Curaçao, hier in I812 ontstaat, een rampjaar voor Caracas, de hoofdstad van Venezuela. Als gevolg van een natuurramp, een aardbeving, vestigt zich hier de Schot William Lee, die in Caracas een drukkerij heeft gehad, die bij die aardbeving verloren is gegaan.

Het is interessant te memoreren dat deze eerste versie van de tegenwoordige drukkerij heeft gestaan in de Herenstraat, op de bovenverdieping van wat nu de Ritz Soda Fountain is. De drukkerij was nogal honkvast, omdat zij pas $\mathrm{II}_{7}$ jaren later verhuisd is naar één der gebouwen bij de wallen achter de protestantse kerk in Fort Amsterdam. In I950 heeft men het moderne en uitstekend geoutilleerde gebouw aan de inmiddels naar William Lee genoemde straat betrokken.

Men kan zich het grote evenement voorstellen: de verschijning in I8I2 van het eerste op Curaçao zelf verzorgde drukwerk, met name het eerste nummer van de toen nog The Curaf̧ao Gazette and Commercial Advertiser genoemde krant van William Lee.

Pas in 1843 , dus 31 volle jaren daarná, zou Curaçao een tweede drukkerij rijk worden. Gek, voor onze verwachtingen althans, is dat die drukkerij niet in de stad is gekomen, maar ver buiten haar grenzen, op Barber. Deze tweede drukkerij is geworden de eerste van het Vicariaat, gesticht door Mgr. Niewindt.

$\mathrm{Nu}$ dringt zich onmiddellijk de vraag op of Monseigneur Niewindt niet eerder een drukkerijtje, hoe bescheiden dan ook, moet hebben gehad. Immers, in 1825 verschijnt er van zijn hand een catechismus, die de christelijke leer in de landstaal brengt. De eerste joodse catechismus (J.H.M. Chumaceiro) is van veel later, gevolgd door Sendero de la fe van M. N. Nathan in I9II.

Het staat vast dat de roomse catechismus - primitief van druk - op het eiland zelf is gedrukt. Bij Lee soms? Dit is een open vraag, die waarschijnlijk nimmer beantwoord zal (kunnen) worden omdat men toen al de slechte gewoonte had drukkerij, uitgever en datum niet op de boeken e.d. te vermelden.

Van de bescheiden pers, die het geval van Barber moet zijn geweest, rolden al spoedig de eerste exemplaren school- en kerkboeken. In de loop der jaren zou deze drukkerij - laat ik zeggen in haar tweede lezing - uitgroeien tot een van de best geoutilleerde van het eiland, waar dag- en weekbladen alsmede andere belangrijke drukwerken verzorgd werden. 
Ongelukkig genoeg is geen spoor meer te bekennen van drukwerken van deze drukkerij afkomstig, behalve dan de catechismus waarvan er zo net sprake is geweest, en waarvan één exemplaar nog in het archief van het Vicariaat, thans Bisdom, berust.

De drukkerij van het Vicariaat, later PAULUSDRUKKERIJ geheten, heeft onnoemelijk veel werken in de landstaal gedrukt en soms ook wel uitgegeven en is, in verband daarmee, van belang in het kader van het boek in Curaçao's verleden.

De drukkerij, echter, die ons eiland vermaardheid in het buitenland, in de eerste plaats in Zuid-Amerika, heeft bezorgd, is de drukkerij van de firma Agustín Bethencourt e Hijos. Deze firma is het geweest, die, feitelijk, Curaçao heeft gemaakt tot cultuurcentrum, van waaruit het boek zijn weg vond naar de meeste landen van Zuid-Amerika. Hoe ongeloofwaardig dit moge klinken, Venezuela, Colombia, Cuba, Mexico, Chili, Argentinië en andere landen zijn jarenlang afhankelijk geweest van Curaçao voor wat hun boeken en ander drukwerk betreft.

Ook op het gebied van het boek vinden wij weer parallellen met de tijd waarin Curaçao, thans een dor eiland en dorstige woestenij zou men haast kunnen zeggen, de korenschuur is geweest van de Spaanse nederzettingen in Zuid-Amerika: mais, groenten, vruchten, hout, schapen, geiten en koeien werden door Curaçao uitgevoerd. De tijden zijn veranderd en Curaçao ziet zich genoodzaakt in zijn eerste levensbehoeften te voorzien door etenswaren in te voeren.

In september I96o zal het roo jaar geleden zijn dat Agustín Bethencourt, Spanjaard afkomstig van de Kanarische Eilanden, op Curaçao is aangekomen. Zijn drukkerij ontstond pas enkele jaren later. Bethencourt is, eigenlijk, per toeval hier gekomen; van een bewust immigreren is dus geen sprake geweest. In Venezuela waar hij als vele van zijn landgenoten aankwam, wilde het na jaren maar niet naar zijn zin vlotten en, ten einde raad, besloot hij terug te keren naar zijn geboorte-eiland. In Willemstad heeft hij op scheepsgelegenheid moeten wachten en van zijn oponthoud hier heeft hij, actief en slagvaardig als hij was, gebruik gemaakt om te beginnen, eerst, met een zaak en muzieklessen, later, met een boekhandel, die spoedig een eigen drukkerij had.

De drukpers en andere drukkerijoutillage liet hij uit de Verenigde Staten komen en aanvullen met materiaal dat hij had betrokken van de oude, dus eerste, Drukkerij van het Vicariaat. 
Jammer is dat men bij een poging een nauwkeurige lijst samen te stellen van wat er al zo door Bethencourt en Zonen op ons eiland is gedrukt, spoedig vastloopt tegen wat ik zou willen noemen de muur der slordigheid en gebrek aan interesse om oude dingen, die van culturele waarde zijn, te bewaren. De firma Bethencourt, die nu nog bestaat, heeft zelf zo goed als niets meer van wat vroeger bij haar is gedrukt en/of uitgegeven.

Het enige kleinood, relikwie zou men het haast kunnen noemen, is een receptenboek van eind vorige eeuw, waar Mevrouw de Weduwe van Ricardo Bethencourt erg zuinig op is. Bij andere bibliofielen, onder wie de heer S. A. L. Maduro, heb ik nog het een en ander kunnen vinden. Met zijn toestemming worden dan ook boeken, boekjes en andere geschriften uit zijn verzameling ten toon gesteld naast werken, die de Openbare Leeszaal zelf bezit.

De Bethencourts, vader Agustín en vier zonen: Agustín, Miguel, Rafael en Pascual, begonnen hun zaak in het pand dat nu staat op de hoek van het Helfrichplein en de Kerkstraat. Later, toen Ricardo Bethencourt, kleinzoon van de oprichter, het bedrijf in handen kreeg, is men verhuisd naar het pand in de Herenstraat, dat de firma nu nog heeft.

Het heengaan van Agustín Bethencourt senior, op I4 juni I885, is de dood geweest van een vooraanstaand man, van een hoogstaande en beminde figuur, waar heel Curaçao om heeft gerouwd, zoals blijkt uit krantenberichten uit die dagen. Getuigenis hiervan vinden wij ook in een gedenkboekje dat bij die gelegenheid is uitgegeven onder de titel Corona Funebre (Rouwkrans). Een gehavend maar daarom niet minder zorgvuldig en liefdevol bewaard exemplaar hiervan is, mij door de heer S. A. L. Maduro in bruikleen afgestaan.

De vele eigenschappen, die de heer Bethencourt als mens, als kunstenaar, als ondernemend zakenman, als vriend hebben gesierd, worden in dit boekje belicht. De hierin opgenomen monografieën worden gesigneerd, o.m. door Dr. Capriles, L. M. Díaz, Victor Antonio Zerpa, A. Braschi, José Serrano, J. Quintero, terwijl de dichter Joseph S. Corsen in een sonnet uiting geeft aan zijn gevoelens van medeleven.

Van bijzondere betekenis voor het culturele leven op Curaçao is geweest het initiatief van Bethencourt, in I 868 genomen, om een 'muziekwinkel' (Almacén de Música) in te richten. Hierbij werden verkrijgbaar gesteld muziekstukken uit het buitenland alsmede partituren door hem zelf gedrukt en uitgegeven. Maar 
niet alléén tot het uitgeven en verkopen van muziekpartituren heeft Bethencourt zich beperkt. Hij is bijzonder actief geweest in het stimuleren van jonge mensen die zich aangetrokken voelden tot de muziek. Met de heer Carl Fensohn - mijn jeugdgenoten en mij nog persoonlijk bekend - richtte Bethencourt hier een strijkkwartet op, welk voorbeeld spoedig navolging vond.

In het voorwoord waarmee Bethencourt zelf de catalogus (vierde editie, I877) van zijn Muziekwinkel inleidt, schrijft hij: "nuestro almacén de música no tan sólo ha sido útil a Curaçao, sino a muchos pueblos de las Repúblicas y de las Antillas vecinas, en donde se notan los grandes progresos que se hacen en el bello arte de Euterpe". (Onze muziekwinkel is niet alléén nuttig gebleken voor Curaçao, maar ook voor vele nabuurlanden, Republieken en Antillen, waar de grote vooruitgang, die men maakt op het gebied van de schone kunst van Euterpe, duidelijk merkbaar is).

Grote bekendheid heeft in zijn dagen gehad het door Bethencourt uitgegeven Boletin de la Libreria. Dit veertiendaagse bulletin van zijn boekhandel was bedoeld als officieel orgaan van de uitgeverij. Hiervan wordt gezegd, dat het graag gelezen werd op Curaçao zowel als in het buitenland. Door Bethencourt is hiermee de grondslag gelegd voor de dagbladpers. Jaren later is, immers, uit deze Boletín de la Libreria, Curaçao's eerste dagblad, Boletín Comercial voortgekomen, nadat het eerst een tijdlang (I897I908) als Diario del Comercio bekend heeft gestaan.

$\mathrm{Na}$ het te hebben gehad over Bethencourt, dringt zich als vanzelfsprekend de naam van Douwe Zalm aan ons op. Zalm is, n.l., een leerling geweest van Bethencourt. Ook heeft hij een tijdje gewerkt bij Cornelis Gorsira, eigenaar van de Drukkerij De Curaçaosche Courant. Douwe Zalm is ook de man die een omwenteling teweeg brengt in het drukkerijwezen op Curaçao, een omwenteling, die van zeer veel en zeer gunstige invloed is geweest op de productie en verspreiding van het boek.

$\mathrm{Hij}$ bestaat het namelijk om te beginnen met de mechanisatie van het bedrijf, eerst de toenmalige TIPOGRAFía AMERICANA, en toen, in 1928, door samen met Jorge B. Suares en Gilberto Z. de Jongh de TIPOGRAFía ElÉctriCA op te richten, Curaçao's eerste drukkerij met electrisch-aangedreven drukpersen en andere outillage.

Zijn 'thuisdrukkerijtje' heeft hij echter nimmer van de hand gedaan. Zo kon het gebeuren dat hij, toen hij zich in 1934 terug- 
trok uit de Tipografía Eléctrica, 'thuis' zich kon blijven bezig houden met het drukken van tijdschriften, boekjes en ander handelsdrukwerk.

Ook de Tipografía Eléctrica (later Ediciones Populares) heeft zich verdienstelijk gemaakt voor het boek op Curaçao. Bij deze drukkerij zijn, behalve twee dagbladen (La Prensa en de Beurs- en Nieuwsberichten in zijn beginperiode), ook boeken en tijdschriften (o.m. De Passaat) verzorgd. De op electrische kracht lopende drukpersen en outillage hebben, in een tijd toen andere plaatselijke drukkerijen dit nog niet konden, het mogelijk gemaakt niet alléén boeken te drukken maar ook schoolschriften en gelinieerd boekhoudmateriaal te leveren aan scholen en plaatselijke handel.

Tot slot dient vermeld te worden het werk dat op het terrein van het boek gepresteerd is door een andere drukkerij, met name die van het Jongensweeshuis SCHERPENHEUVEL, sinds enkele jaren bekend als het Internaat Scherpenheuvel. Vele boeken zijn, vooral in de laatste vijftien à twintig jaar, van de persen van Scherpenheuvel gekomen. Aan het hoofd van dit zeer goed geoutilleerde bedrijf staat een kundige vakman, Frater Auxentius, die zich met liefde wijdt aan het vak.

Niet iedereen zal het met mij eens zijn, maar de hoop is gegrond dat er velen zullen zijn onder mijn toehoorders, die mijn mening kunnen delen als ik zeg dat ik hou van 'oude vrienden, oude wijn en oude boeken'. Geen van de drie ligt voor het opscheppen; hun behoud is niet altijd gemakkelijk.

Van de vele boeken, die op Curaçao zijn gedrukt sinds de persen van de eerste drukkerij hier zijn begonnen te draaien, zijn maar een paar achterhaald, vaak in een deerniswekkende toestand. Over het algemeen vindt 'men' dat die oude spullen, rommel, maar het huis uit moeten, met het gevolg dat wij nu zitten zonder bewijsstukken ter staving van een oude, vervaagde cultuurtoestand van uiting en beleving op ons eiland, een cultureel leven dat ons eigenlijk met trots dient te vervullen.

De activiteiten ontplooid door de Drukkerij van Bethencourt en die van het Vicariaat; de Imprenta del Comercio,de Imprenta Internacional, Douwe Zalm, Drukkerij Scherpenheuvel, Tipografía Eléctrica (Ediciones Populares) en Tipografía Americana zijn evenzovele stimulansen voor ons cultureel leven. In hoeverre 
dit, in wezen, het geval is, is nog een open vraag. Ik kan alleen maar hopen dat deze vraag op positieve wijze beantwoord zal kunnen worden door een van de sprekers die, over een jaar, vanaf deze plaats het woord tot $\mathrm{u}$ zal richten bij de opening van de Boekenweek I96r.

Gelukkig omvatten de oude boeken en drukwerken die nog achterhaald zijn, een keur van onderwerpen. Hierdoor is een inzicht te verkrijgen van wat er al zo op dit gebied is gedaan vroeger. De onderwerpen van deze drukwerken vormen de verscheidenheid zelve. Van godsdienstige verhandelingen (joods, protestants en rooms) tot een leerboekje voor de quadrille (dans) toe, bestrijken deze werken; bijbeltekstverklaringen in het Engels, Eenige mededeelingen aan allen die belangstelden in den bazaar, ten voordeele van het Protestantsche Weesfonds te Curafao, het Eeuwfeest van Bolívar, een overlijdingsgedenkboek, een praatje over het aanroepen van heiligen, minnedichten, beknopte spraakkunst van het papiamento, een joodse catechismus, oeuvres van polemische aard, een verslag van een Colombiaanse Consul op Curaçao aan zijn Minister van Buitenlandse Zaken, een toeristengids van Curaçao, novellen en romans, enz.

Zij zijn gesteld in het Papiamento, Nederlands, Engels en Spaans, de vier meest gangbare talen op ons eiland, toen en nu.

Het zou ondoenlijk zijn zelfs de weinige boeken, die wij in Curaçao's verleden nog levend tegenkomen, uitvoerig te bespreken of er een lijst van op te sommen. Volstaan kan worden met het licht te doen vallen op enkele, naar mijn smaak, interessante werkjes. De rest van de verzameling zullen mijn geachte toehoorders straks zelf kunnen bekijken. Een echte boekenvriend bekijkt liever zelf een boek dan dat hij er over zou moeten horen spreken.

De drie werken waarop mijn keus is gevallen boeien mij en, naar ik hoop, ook anderen, om zeer uiteenlopende redenen. Het ene om zijn typografisch verzorgd voorkomen; het tweede vanwege zijn inhoud en het derde om het pittoreske dat erin te onderkennen valt. De titels zijn: Compendio de la gramática del papiamento door N. J. Evertsz, en De Vrouw uit een practisch, maatschappelijk en zedelijk oogpunt beschouwd, door W. C. Grünings, en Staaltjes van eigen bodem - Muestras del propio suelo, van dezelfde schrijver, niet het minst belangrijk om het feit dat wij te doen hebben met een tweetalige uitgave (Nederlands-Spaans). 
In Curaçao's verleden is een ontmoeting met het boek, d.i. het tastbare, het materiële boek, dus, hélaas, niet zo gemakkelijk als dit met het materiële boek mogelijk is in het verleden van andere landen. Onze eilanden hebben tot voor kort de minder goede gewoonte gehad alles wat oud was - oude boeken, oude meubels, manuscripten en muziek - maar weg te doen of hun onderhoud grovelijk te veronachtzamen.

Gelukkig is het echter weer zó dat er toch nog mensen zijn, volbloed Antillianen niet uitgesloten, die het een en ander hebben bewaard, opgetekend, onderzocht en verzameld. Bij de aanvang van de boekenweek 1960 is een woord van waardering en dank, een eresaluut, aan deze mensen, zeker op zijn plaats.

Namen zoals die van Wein Hoyer, Nicolaas van Meeteren, de paters Euwens en Wahlen, die ons zijn voorgegaan in de dood, en onder die nog in leven zijn de heren Mongui (S.A.L.) Maduro en Jossy Maduro alsmede de heer Maurice Nouel, kunnen nimmer door ons vergeten worden. Hun liefde voor het boek, hun warme belangstelling voor de cultuurproducten van eigen bodem, zijn een lichtend voorbeeld voor ons allen.

Moge de boekenweek I96o, die wij hedenavond inluiden er toe bijdragen om onze mede-eilandbewoners bewust te maken van hetgeen er nog voor het boek gedaan kan en moet worden. Een volk dat zich de potentiële waarde bewust is van het boek als cultuurdrager, als verspreider van gedachten, inzichten, menselijk vernuft, idealen en kennis van de medemens, zal zeker waken voor de toekomst van het boek.

Hoe zeer moderne middelen van contact - radio, televisie, film, microbibliotheken en hemerotheken, naast verzamelingen van speelplaten - de gemeenschap ook stormenderhand veroveren, het einde van het boek is zeker niet nabij. Het boek zal zich, stellig, weten te handhaven, ondanks alles.

En wellicht om reden dat, de gemakzucht die de mens eigen is ten spijt, er iets ondefinieerbaars uitgaat van het contact met het boek zelve, een bekoring waar moeilijk weerstand aan te bieden is.

Curaçao heeft veel aan het boek te danken. Het boek zelf heeft, voor wat betreft zijn materiële totstandkoming en verspreiding in Zuid-Amerika, vaak erg veel te danken aan Curaçao. In het verleden van dit eiland rijst het boek dan ook op als een obelisk van realiteit, een culturele wegwijzer en gedenksteen, die onze banden met de nabuurlanden uitbeeldt en benadrukt. Wij heb- 
ben niet alléén van onze buren ontvangen, maar wij hebben ook gegeven.

Moge dan dat verleden ook de kiem van onze toekomst inhouden, zodat, als de fenix-vogel weleer, ook het boek uit Curaçao's verleden herrijze uit zijn as, opdat de toekomst van ons eiland innig verbonden moge zijn met een briljante toekomst van het boek - niet alléén het boek in zijn absolute en abstracte betekenis, maar ook het boek in materiële, kunsttechnische en zuiver typografische zin. 